\title{
IMPACT OF NYLON INSERTS FOR THE LOCATOR ATTACHMENT ON FUNCTIONAL ADAPTATION FOR MANDIBULAR OVER DENTURE WEARER (ELECTROMYGRAPHIC ANALYSIS)
}

\author{
Hala Mohamed Abd El Hameed*
}

\begin{abstract}
Purpose: This research investigated the effect of two nylon inserts for the locator attachment with different retentive values on oral rehabilitation for the patients wearing mandibular overdenture regarding their muscular activity.
\end{abstract}

Materials and methods: Six complete maxillary and mandibular overdentures were delivered to six healthy male patients. Two implants were installed in the canine region via computerized surgical stent. The mandibular overdentures were retained by locator attachment.

Grouping of the study were done according to the used retentive nylon insert of the locator attachment

Group 1: All the patients used blue nylon inserts for three months

Group 2: the same patients used pink nylon inserts for another three months, with one month rest period interposed between the used blue \&pink nylon inserts .

The impact of these types of nylon inserts on the activity of masseter \& temporalis muscles was investigated via electromygraphic analysis.

Results: ANOVA test revealed improvement for all patients in tested muscles activity expressed as EMG records considering amplitude of these muscle during clenching and chewing hard \&soft food either for blue or pink nylon inserts with statistical significance between different measuring periods. Paired t-test proved that pink insert provides significant improvement in muscular activity than the blue one at $\mathrm{p} \leq 0.05$.

Conclusion: Depending on the investigation of this study, it be concluded that the retentive system used in the locator attachment has great impact on oral rehabilitation regarding the patients' muscular activity. Increasing the retentive power of the attachment enhance the patient's muscular activity.

\footnotetext{
* Associate Professor of Prosthodontics, Faculty of Dentistry Suez Canal University
} 


\section{INTRODUCTION}

The construction of complete denture was the sole solution for the edentulous arch for several decades. This treatment expedience faced several problems particularly in the lower jaw. The diminished area of coverage, salivary flooding action and also the activity of the tongue leads to unstable prosthesis, then cause lack of self reliance and reduction in chewing potency. ${ }^{1}$

Regardless appropriate denture procedures it is not conceivable in many instances to attain ideal denture retention and stability. This perhaps due to poor jaw relationship, psychological situation, diminished neuromuscular coordination, ineffective quality and quantity of obtainable bone and alveolar mucosa, or ineffective vestibular depth. ${ }^{2}$

Researches confirmed that dental implants can be effectively placed and established with a range of prosthetic designs to rehabilitate wholly edentulous patients. It has the evidence to be dependable, efficacious and safe. ${ }^{3}$

Priorities of implant supported over denture over complete denture are; support, stability, mastication and phonation are considerably improved. Retention of the prosthesis is promoted by the use of mechanical attachment without maximum soft tissue coverage and prostheic extension .All these factors are very serious for denture wearers and the patients with bony exostoses or low gagging thresholds. The ability to fragmentize through food with the ultimate biting force and intensification of the chewing ability is of their prime concern. ${ }^{4}$

Locator attachment, has been widely and successfully used .This attachment is self-aligning, has dual retention and is accessible in different colors for nylon insert with different retention values, in relation to degrees of implants divergence. In addition to precise repairing and replacement. Resiliency is one of the significant features of locator attachment, that permit movement in both the vertical plane and hinge axis. ${ }^{5,6}$
Slightly oversized central stud male insert in contrast with inner metal ring of the female portion provides mechanical and frictional retention manner for locator attachment to be introduced by press-fit manner. The outer margin completely captures and coincides with the shallow undercut area in the female portion. ${ }^{7}$

Oral rehabilitation treatment has direct effectiveness on diverse structures, involving muscle activity. This might happen because rehabilitating mediation was carried out in the oral cavity, as is it a part of the stomatognathic system, in which all structures function in harmonious manner. ${ }^{8,9}$

The electromyographic system is a graphic registration device measuring the electrical potentials of muscle units ,for observation and estimating the muscular electrical activity of the muscular system as they organized with mandibular movements. ${ }^{10}$

Electromyographic (EMG) activity of masseter muscle in implant supported overdenture wearers through manducating hard and soft food, investigated that intervention with implant-retained mandibular dentures brings more uniform chewing modalities with greater electrical activity of the masseter muscles, thus yielding improved and comfortable chewing function.$^{\mathbf{1 1 , 1 2}}$

This study inspected the postulation that more denture retention adjusts the masticatory function, assuming that the retention of the overdenture primarily relay on the used attachment system . The present study aimed at evaluation of the influence of two different nylon inserts of the locator attachments on the muscle activity during chewing and clenching.

\section{MATERIALS AND METHODS}

Six complete maxillary and mandibular dentures were delivered to six healthy male patients elected from outpatient clinic of the Prosthodontics Department, Faculty of Dentistry, Suez Canal 
University. Two weeks later, and after occlusal refining patient were introduced for establishing the computerized surgical stent as follow:

\section{i) Fabrication of radiographic template:}

Duplication of lower denture for every patient was done utilizing silicon putty consistency(Zetaplus. C-silicone putty, Zhermack company- Italy) in a appropriate sized plastic container. After setting of the rubber base, the denture was taken away, and the mold was filled by radio-opaque acrylic resin that was prepared by mixing auto polymerizing acrylic resin with barium sulfate (Elnasr pharmaceutical chemicals co, Egypt) at a quantative relation of 3:1. After complete setting of the resin, the stent was removed finished and polished. Small channels were formulated among the long axes of each prosthetic tooth to seem as radiolucent lines in the CBCT image. Stability and fitness for radiographic stent were examined in the patient's mouth (Fig.1A).

\section{ii) Preoperative radiographic imaging:}

A preoperative Cone-beam computed tomographic (CBCT) image was taken for the patient's edentulous arches, while he closing his upper denture on lower radiographic template by the help of vinyl polysiloxane (VPS) bite index interposed between them in centric relation at a slightly higher vertical dimension.

The produced image was gained as digital imaging and communications in medicine (DICOM) data on a compact disc and delivered to the blue sky plan software(Blue Sky Plan3 (version 3.39.4), BlueSkyBio- America.)

\section{ii- Optical scanning:}

By an optical scanner (Eco scan 7 series, SHERA- Germany), the mandibular models were scanned alone followed by $2^{\text {nd }}$ scanning for same the models with the radiographic template fitted on them.
The two previous scans in addition to the preoperative CBCT were imported to the blue sky plan3 software to plan the optimum implants position (Fig.1B)

\section{iii) Virtual implants and surgical stents planning:}

The previous optical scanning were superimposed over the CBCT. Virtual Implants were placed in accurate prosthetic positions directed by the radiolucent channels in the radiographic stent at the canines position with proper estimation of parallelism between the implants, the available bone and approximation of vital structures at each implant site.

Stent fixation were planned by three fixation screws that distributed equally anteriorly and posteriorly in the mandibular arch. A guide tube with a proper size was selected for each implant and fixation screws (Fig. 1C).

\section{iv) 3D printing for surgical guide:}

The virtual surgical stents were selected and exported solely as a standard tessellation language (STL) file and sent via an e-mail to the additive manufacturing machine (Zenith 3D printer, Kore). for $3 \mathrm{~d}$ printing into the computerized surgical stent (Fig 1D).

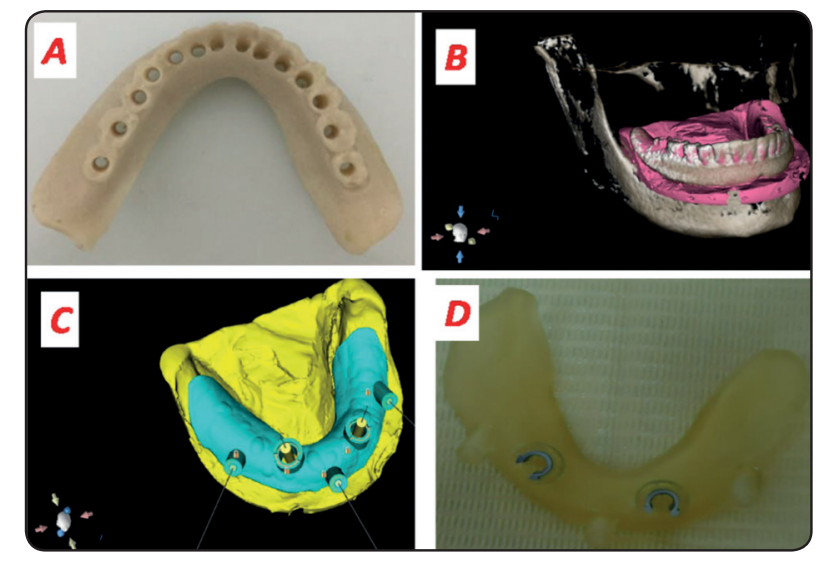

Fig. 1A; radiographic template, fig.1B; superimposing the optical scanned radiographic template over the CBCT , fig.1C; The virtual surgical stent over the scanned cast, fig1 D; Computer guided surgical stent. 


\section{Osteotomy preparation and implant installation}

Two root form, threaded and tapered dental implants (Cleanlant s-Clean -Dentis. Korea) were selected .The surgical guide was checked for proper extension and stability and fixed to the underlying supporting structure by the silicon bite followed by fixing screws that were adjusted into their positions by anchoring twist drill that previously used for providing their pathway . (Fig 2A)

Drilling was achieved via the computer guided surgical kit. Partial succession drill guided surgery was carried out; starting drill then pilot drill for providing full length osteotomy. Widening the osteotomy site by the intermediate drill was done using intermittent pressure with plenteous irrigation (Fig 2B) . Following that, removal for the fixation screws and surgical stent was carried out . Final free hand drilling from the universal surgical kit was done to terminate the osteotomy preparation . The mounted implant was inserted manually into its prepared position until tightening met resistance. Fixture tightening was completed by torque ratchet till $35 \mathrm{Ncm}$ by threading the implant in a clockwise direction until the implant top flushed with the bone surface. The implant's cover screw was tightened for covering the implant fixture.

Relieving the denture against the fixture location was carried out ,and relined with a tissue conditioning material. Following that about three months laters and after affirmation of the osseointegration, the patient introduced for obtaining the attachment.

\section{Application of locator attachment:}

The attachment( Dentis; Kerator, New York, USA) including the abutment with a metal housing cap and retention nylon inserts with different colors that reflect their retention forces, $\{$ the blue (extra light), pink (light)\} (Fig 2C).

The selected attachments were unpacked and the abutment was engaged into the implant, threaded and tightened into the implant internal hex by using abutment driver, then further torque was achieved using torque ratchet (Fig 2D)

A white spacer was positioned over the head of each abutment. The metal housing with black processing insert was placed onto each abutment to be incorporated to the fitting surface of the lower denture by direct pickup technique.

Before replacement by final retention insert the patients were allowed to use their overdenture at least for one months.

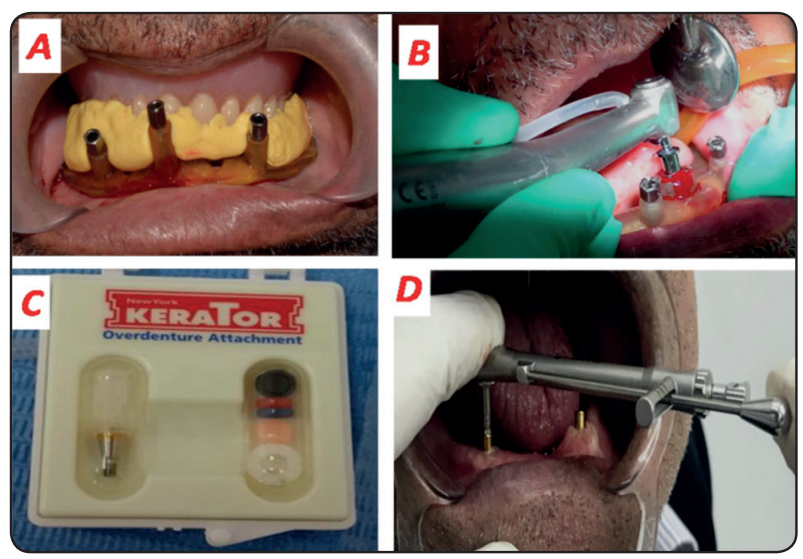

Fig. 2A; Surgical guide fixed by fixation screws., fig 2B; Drilling through the surgical guide., fig.2C; Abutment and nylon inserts., fig 2D; Ratchet for abutment tightening.

Grouping of the study were done according to the used retentive nylon insert of the locator attachment

Group 1: All the patients used blue (extra light retention, 1.2 pounds) nylon inserts for three months

Group 2: the same patients used pink (light retention, 2.4 pounds) nylon inserts for another three months.

Between using the blue and pink nylon insert all patients were allowed for one month rest period, where the black processing caps were placed in the metal housing alternative to the retentive inserts during this rest period.

Seating tool was used to push the retention insert into the metal housing after removal of the black processing one.(Fig,3 A\&B) 


\section{Electromyographic evaluation:}

Surface electromyography (sEMG) carried out by Neuro-MEP-Micro, version 2015, model 3.5.12.0 (32-bit), 2-channels EMG and evoked potentials (EP) digital neurophysiological system software, Neurosoft Ltd, Russia.

Five recordings were obtained from both masseters and temporalis muscles as following:

Baseline record, after one months from attachment incorporation with black processing male insert (total disappearing of any inconvenience and patients were customized to their dentures).

Second and third records, after one and three months from using blue inserts respectively.

- Patients were allowed for one month rest period without retentive inserts.

- Fourth and fifth records, after one and three months from using pink inserts respectively.

EMG disposable adhesive surface electrodes were used for the recording muscle activity. Upon cleaning and rubbing the patient's skin with cotton and gel-based cleaner, the inner side of the electrode was lined with conductive gel and sealed by adhesive tape. The active electrodes have been mounted in similar positions for all subjects as follows:

* On the most functional part of the mastication muscles (motor point) during clenching.

* One $\mathrm{cm}$ behind the palpated anterior border, parallel to the main direction of the masseter muscle fibers(Fig3C)

* For temporalis muscle the active electrode positioned just in front of the anterior border of the hairline in the region of greatest lateral distension (Fig3D)

The reference electrode that is caudal to the active one, was positioned on the ear lobe, with at least 30-40 $\mathrm{mm}$ inter-electrode distance and the ground electrode was adjusted around the wrist.

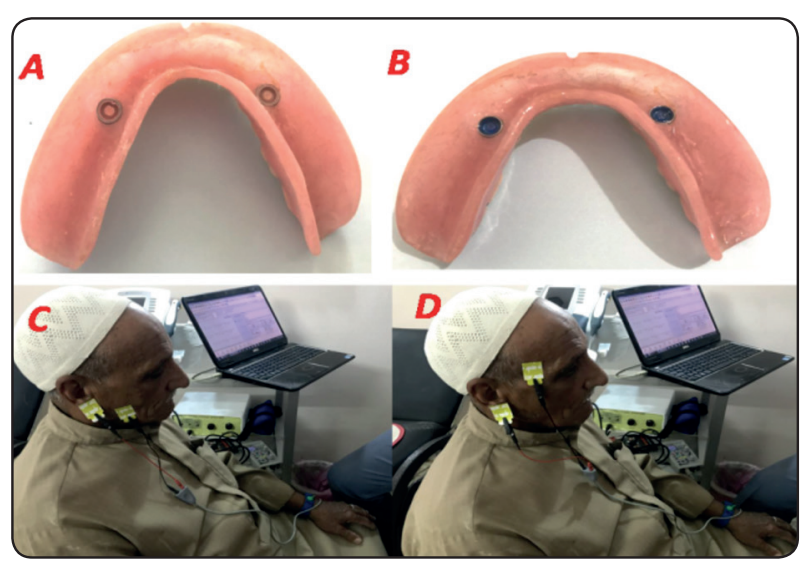

Fig. 3A \& B pink\&blue nylon inserts. Fig; 3C\&D; measuring muscular activity

Anatomically related transparent sheet for each patient was used for repositioning of active electrodes in their exact position in all appointments.

The obtained EMG results from electrophysiological software were installed on portable computer.

Electromyographic Technique: The patients were sitting with their head unsupported, preserving a normal erected position. The patient asked to clench with the teeth in centric occlusion, and guided to clench as hard as possible, keeping the contraction for 5 seconds. Recording EMG activity of masseter and temporalis muscle for both sides during clenching and chewing equally-sized pieces of banana and carrot as soft and hard food respectively has been established. He was informed to place one piece / time in the same position of one side and chew it. For each session four records of each muscle were carried out at each performance. Five minutes were left between each record to avoid muscle fatigue. The peak to peak amplitude of each muscle was then recorded and the mean values for both muscle were calculated for chewing and clenching at different measurements periods. This mean value considered as indication for the mean muscular activity of the patient. The findings were quantified by the data acquisition software, expressed in microvolts $(\mu \mathrm{V})$ then statistically analyzed . 


\section{RESULTS}

The data were collected and statistically analyzed using two way ANOVA (analysis of variance ,SPSS ,Chicago, IL, USA). Subsequently, Turkey's post hoc tests were used for pair wise comparisons of results. The significance level was set at $p \leq 0.05$ and highly significant at $\mathrm{P} \leq 0.01$ level.

The mean values of recorded EMG muscle activity in microvolt were calculated as the average results obtained from both masticatory muscles at both sides during each measurements.

Table (1) proved that the blue nylon insert shows improvement for all patients in tested muscles activity expressed as EMG records considering the amplitude of these muscle during clenching (static) and chewing (dynamic) of soft food (banana) and hard food (carrot) between starting measurement (baseline) without nylon insert and $\{1 \mathrm{st}$, and 2 nd measurement period respectively from insertion of the blue nylon inserts\} of the locator attachment. Statistically, ANOVA test reveals improvement in the amplitude of muscle activity MUAPs was highly significant during clenching $\mathrm{p}=0.003$, chewing of soft food $\mathrm{p}=0.002$ and hard food $\mathrm{p}=0.013$ between different measurement periods.

Using pair wise comparisons test, it was postulated that there were significant difference between each two measuring periods separately either for clenching or chewing both soft and hard food as $\mathrm{p} \leq 0.05$.

Again from table (2) the pink nylon insert showed mush better perfection in muscle activity. Statistically, ANOVA test reveals, highly considerable improvement in the amplitude of muscle activity MUAPs during static and dynamic tests, as $\mathrm{p} \leq 0.000$ for clenching, chewing soft and hard food between different measurement periods. Regarding pair wise comparisons test ; the significant difference between each two separate measuring periods was found as the blue one as well.

\section{Comparison between blue and pink nylon inserts}

The obtained data were collected, tabulated and statistically analyzed using (paired sample $t$ test) as means, \pm standard deviation (SD), $\mathrm{P}$-value which is considered significant at $\mathrm{P} \leq 0.05$ level.

TABLE (1) Mean amplitude of muscular activity with blue nylon insert

\begin{tabular}{|c|c|c|c|c|}
\hline \multirow{2}{*}{} & \multicolumn{3}{|c|}{ Blue nylon insert (group 1) } & P -value \\
& $\begin{array}{c}\text { base line } \\
\text { mean } \pm \text { SD }\end{array}$ & $\begin{array}{c}1 \text { st M } \\
\text { mean } \pm \text { SD }\end{array}$ & $\begin{array}{c}\text { 2nd M } \\
\text { mean } \pm \text { SD }\end{array}$ & $0.003^{* *}$ \\
\hline Clensh & $145.53 \pm 7.8$ & $169.92 \pm 12.76$ & $185.73 \pm 10.56$ & $0.002^{* *}$ \\
\hline soft food & $165.06 \pm 9.2$ & $197.19 \pm 8.5$ & $225.35 \pm 16.3$ & $0.013^{* *}$ \\
\hline hard food & $179.83 \pm 11.03$ & $230.4 \pm 14.7$ & $261.38 \pm 12.02$ & \\
\hline
\end{tabular}

$*$ Significant p-value $\leq 0.05, * *$ highly significant p-value $\leq 0.01$

TABLE (2) Mean amplitude of muscular activity with pink nylon insert

\begin{tabular}{|c|c|c|c|c|}
\hline & \multicolumn{3}{|c|}{ Pink nylon insert (group 2) } & P -value \\
\hline & $\begin{array}{c}\text { base line } \\
\text { mean } \pm \mathrm{SD}\end{array}$ & $\begin{array}{c}1 \mathrm{st} \mathrm{M} \\
\text { mean } \pm \mathrm{SD}\end{array}$ & $\begin{array}{c}\text { 2nd M } \\
\text { mean } \pm \mathrm{SD}\end{array}$ & $0.000^{* *}$ \\
\hline Clensh & $145.53 \pm 7.8$ & $184.04 \pm 7.86$ & $204.32 \pm 21.8$ & $0.000^{* *}$ \\
\hline soft food & $165.06 \pm 9.2$ & $232.26 \pm 13.51$ & $251.58 \pm 18.06$ & $0.000^{* *}$ \\
\hline hard food & $179.83 \pm 11.03$ & $266.73 \pm 12.4$ & $282.81 \pm 15.44$ & \\
\hline
\end{tabular}


From table (3) and Fig (4), the pink nylon insert showed mush better advancement in muscle activity than that of blue one either in the first or second measuring periods during static and dynamic muscular performance .Statistically pink inserts shows significantly higher amplitude of the MUPs during chewing hard food only in the $1^{\text {st }}$ measuring period. Non significant difference was observed in either in clenching or chewing soft food in comparison to the blue insert during $1^{\text {st }}$ measuring period. Statistical significant difference was observed in the $2^{\text {nd }}$ measuring period in all masticatory performance in favor to the pink insert as $\mathrm{p} \leq 0.05$.

TABLE (3) Mean amplitude of muscular activity between pink and blue nylon inserts

\begin{tabular}{|c|c|c|c|c|c|c|}
\hline \multicolumn{2}{|c|}{} & \multicolumn{3}{c|}{$2^{\text {nd } M}$} \\
\hline & $\begin{array}{c}\text { Clensh } \\
\text { mean } \pm \text { SD }\end{array}$ & $\begin{array}{c}\text { Soft food } \\
\text { mean } \pm \text { SD }\end{array}$ & $\begin{array}{c}\text { Hard food } \\
\text { mean } \pm \text { SD }\end{array}$ & $\begin{array}{c}\text { clensh } \\
\text { mean } \pm \text { SD }\end{array}$ & $\begin{array}{c}\text { Soft food } \\
\text { mean } \pm \text { SD }\end{array}$ & $\begin{array}{c}\text { Hard food } \\
\text { mean } \pm \text { SD }\end{array}$ \\
\hline Pink insert & $184.04 \pm 7.86$ & $232.26 \pm 13.51$ & $266.73 \pm 12.4$ & $204.32 \pm 21.8$ & $251.58 \pm 18.06$ & $282.81 \pm 15.44$ \\
\hline Blue insert & $169.92 \pm 12.76$ & $197.19 \pm 8.5$ & $230.4 \pm 14.7$ & $185.73 \pm 10.56$ & $225.35 \pm 16.3$ & $261.38 \pm 12.02$ \\
\hline p-value & 0.14 & $0.002^{* *}$ & 0.07 & $0.038^{*}$ & $0.044 *$ & $0.01 * *$ \\
\hline
\end{tabular}

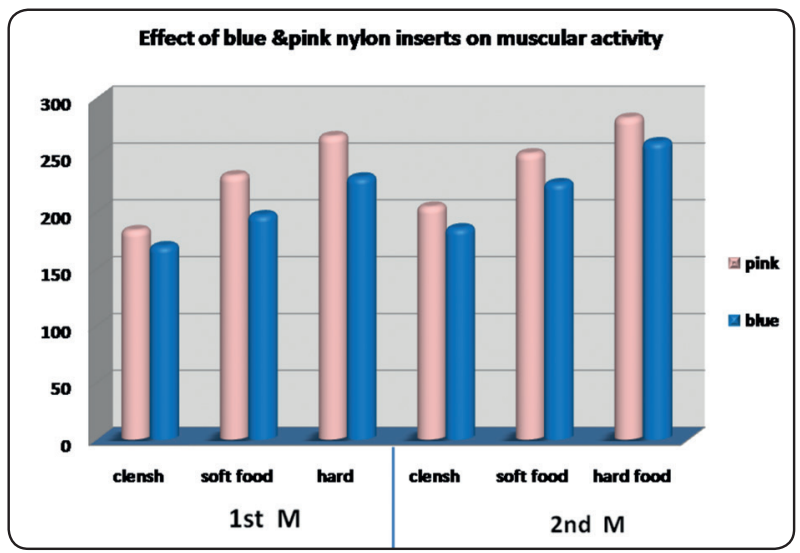

Fig. (4)

\section{DISCUSSION}

One of the choices to reverse the steadiness issue of mandibular dentures is to relate dental implants with the prostheses, creating them implant-supported overdentures. It was postulated that a traditional denture within the upper jaw and mandibular overdenture retained by two dental implants ought to become the primary selection for managing the edentulous patients, because of their advanced age , excessive cost and elongated managing time. ${ }^{13}$

It was promoted that implant supported mandibular overdentures as hopeful standard of care for dynamic rehabilitation of the edentulous masticatory system. ${ }^{14}$

Considering the current study, the radiographic stent was totally made up from of a high barium sulphate containing mixture $30 \%$ for each the denture base and teeth) to permit for easier segmentation because the use of $10 \%$ barium sulphate within the base would need greater attempt to segment it from adjacent bone. ${ }^{15}$

Software was used for designing implant treatment planning. It facilitates the capability of 3D images fabrication, producing a precise and easier superimposition and angular measurements. ${ }^{16}$

Sterio-lithography (SLA), The technology that employed in the current study is the most widely 
used rapid prototyping technology. It supplies many benefits like greatest accuracy, best finished surface, it can manufacture wide varieties of objects with high strength and toughness. ${ }^{17}$

The Locator system has distinct benefits than other attachment including, resiliency ,easy in insertion and removal, and develops a dual retention system through both external and internal mating surfaces affecting the retention and stability of the prosthesis and therefore the masticatory function of the patient. Elsewhere, it include interchangeable nylon insert offering multiple retentive force..$^{18}$

Locator attachment has self-aligning characteristic that is useful in guiding patients once putting their denture. Locator attachments need low maintenance and offer high durability and long lasting performance for over 60,000 insertion cycles (equivalent to 10 years of practical function). ${ }^{19}$

Evaluation of masseter and temporalis muscles carried out in this study as they are the largest and strongest superficial masticatory muscles, that attainable to surface EMG examination. ${ }^{20}$

These records were made on both sides for prevention of any alteration in recorded muscle activity resulting from diversity in the preferred chewing side for each patient. Also, for activating the ultimate number of motor units representing muscle activity. ${ }^{21}$

Several strategies have been introduced to estimate the impact of oral rehabilitations on patients' quality of life .One of them is surface electromyography (SEMG), which consists of a device designed for recording muscle activity during rest or function. Thus, EMG presented an estimation of total energy consumed throughout manduction sequences. So, it is probable to understand which muscles are active and the way they coordinate through various movements, making the comparison of musclar activity prior and subsequent to the placement of different prostheses is possible. ${ }^{12}$
The higher values of muscle activities with chewing soft / hard food relative to clenching ,This could flow from greater muscle activity wanted for performing jaw movements during chewing food. Also, to employ forces needed for cutting and granulating the food.. ${ }^{10,22}$

Higher means of electromyogram activity when chewing hard food in comparison with chewing soft food in current study, supported by another studies which postulated that tougher food consistency needed higher levels of muscle activity because of, higher muscle force required to mash and comminute hard food. ${ }^{23}$

The observed improve within the 2nd measurement after insertion of the retentive nylon insert than the $1^{\text {st }}$ one. This could be related to the gradual advancement of patient's experience, patient acclimation to the new prosthetic appliance, settlement and adaptation of the denture to the underlying structures. Former studies confirmed that, with time muscle retrieved its tonicity, neuromuscular organization with enhanced masticatory efficacy.$^{24,25}$

The less retentive mandibular denture needed greater muscular attempt for its steadiness and thus led to minimal efficient direction-indvidual force for mashing of the food bolus. So, the more retentive and stable overdenture permitted reorganization leading to more efficient masticatory performance, resulting not only in more effective power-strokes but also more active masticatory muscles, characterized by higher amplitude values. This is in agreement with the result of this research as the more retentive pink inserts showed significantly higher EMG values than blue one.$^{26}$

\section{CONCLUSION}

Depending on the investigation of this study, it be concluded that the retentive system used in the locator attachment has great impact on oral rehabilitation regarding the patients' muscular activity. Increasing the retentive power of the attachment enhance the patient's muscular activity. 


\section{REFRENCES}

1. Carlsson GE. Implant and root supported overdentures - a literature review and some data on bone loss in edentulous jaws. J Adv Prosthodont. $2014 ; 6(4): 245-52$.

2. Assunção WG, Barão VAR, Delben JA, Gomes EA, Tabata LF. A comparison of patient satisfaction between treatment with conventional complete dentures and overdentures in the elderly: a literature review. Gerodontology. 2010; 27(2):154-62.

3. Sadowsky SJ, Hansen PW. Evidence-based criteria for differential treatment planning of implant restorations for the mandibular edentulous patient. J Prosthodont. 2014; 23(2):104-11

4. Kang S-M, Lee S-S, Kwon H-K, Kim B-I. Short-term improvement of masticatory function after implant restoration. J Periodontal Implant Sci. 2015 ;45(6):205-9.

5. ELsyad MA,Errabti HM, MustafaAZ. Mandibular Denture Base Deformation with Locator and Ball Attachments of Implant-Retained Overdentures. J Prosthodont. 2016; 25(8):656-64

6. Kleis WK, Kämmerer PW, Hartmann S, Al-Nawas B, Wagner W. A comparison of three different attachment systems for mandibular two-implant overdentures: one-year report. Clin Implant Dent Relat Res. 2010; 12(3):209-18.

7. Kim S-M, Choi J-W, Jeon Y-C, Jeong C-M, Yun M-J, Lee $\mathrm{S}-\mathrm{H}$, et al. Comparison of changes in retentive force of three stud attachments for implant overdentures. J Adv Prosthodont. 2015 Aug;7(4):303-11.

8. Alqutaibi AY, Kaddah AF, Farouk M. Randomized study on the effect of single-implant versus two-implant retained overdentures on implant loss and muscle activity: a 12-month follow-up report. Int J Oral Maxillofac Surg. 2017 ;46(6):789-97.

9. Abdelhamid AM, Hanno KI, Imam MH. A prospective cross-over study to evaluate the effect of two different occlusal concepts on the masseter muscle activity in implant-retained mandibular overdentures. Int $\mathbf{J}$ Implant Dent. $2015 ; 22 ; 1(32): 1-8$.

10. Elsyad MA, Hegazy SAF, Hammouda NI, Al-Tonbary GY, Habib AA. Chewing efficiency and electromyographic activity of masseter muscle with three designs of implantsupported mandibular overdentures. A cross-over study. Clin Oral Implants Res. 2014 ;25(6):742-8.
11. Paphangkorakit J, Chaiyapanya N, Sriladlao P, Pimsupa S. "Determination of chewing efficiency using muscle work." Archives of Oral Biology. 2009 ;53(6):533-7.

12. Abdelhamid A, Hisham Hanno K, Imam M. The effect of two different occlusal concepts on the masseter muscle activity in implant retained mandibular overdentures. Journal of Dental Implants. 2017;7(1):20-7.

13. Awad MA, Rashid F, Feine JS. The effect of mandibular 2-implant overdentures on oral health-related quality of life: an international multicentre study. Clinical Oral Implants Research.2014; 25: 46-51.

14. vonderGrachtI, DerksA, Haselhuhn K, Wolfart S.EMG correlations of edentulous patients with implant overdentures and fixed dental prostheses compared to conventional complete dentures and dentates:a systematic review and meta-analysis.Clin Oral Implants Res. 2017; 28(7):765-773

15. Kumar CA, Kumar CR, Sujesh M, Priyalatha S, Harilal G. Implant placement using CBCT guided stent and conventional stent - A case report. IP Annals of Prosthodontics and Restorative Dentistry. $2018 ; 15 ; 4(1): 9-12$

16. Verhamme LM, Meijer GJ, Bergé SJ, Soehardi RA, Xi T, de Haan AF.. An Accuracy Study of Computer-Planned Implant Placement in the Augmented Maxilla Using Mucosa-Supported Surgical Templates. Clin Implant Dent Relat Res. 2015 ;17(6):1154-63.

17. Giacomo GD, Silva J, Martines R, Ajzen S. Computerdesigned selective laser sintering surgical guide and immediate loading dental implants with definitive prosthesis in edentulous patient: A preliminary method. Eur J Dent. $2014 ; 8(1): 100-6$

18. Uludag B, Polat S, Sahin V, Çomut AA. Effects of implant angulations and attachment configurations on the retentive forces of locator attachment-retained overdentures. Int $\mathrm{J}$ Oral Maxillofac Implants. $2014 ; 29(5): 1053-7$.

19. Tehini G, Baba NZ, Majzoub Z, Nahas P, Berberi A, Rifai K. In Vitro Effect of Mastication on the Retention and Wear of Locator Attachments in a Flat Mandibular Ridge Model. J Prosthodont. 2019 ;28(2):e744-51.

20. Hugger S, Schindler HJ, Kordass B, Hugger A. Clinical relevance of surface EMG of the masticatory muscles. (Part 1): Resting activity, maximal and submaximal voluntary contraction, symmetry of EMG activity. Int J Comput Dent. 2012;15(4):297-314. 
21. SônegoMV,GoiatoMC,DosSantos DM.Electromyography evaluation of masseter and temporalis, bite force, and quality of life in elderly patients duringthe adaptation of mandibular implant-supported overdentures. Clin Oral Implants Res. 2017;28(10):e169-e174

22. Moreno I, Sánchez T, Ardizone I, Aneiros F, Celemin A. Electromyographic comparisons between clenching, swallowing and chewing in jaw muscles with varying occlusal parameters. Med Oral Patol Oral Cir Bucal. 2008;13(3):E207-213.

23. Piancino MG, Bracco P, Vallelonga T, Merlo A, Farina D. Effect of bolus hardness on the chewing pattern and activation of masticatory muscles in subjects with normal dental occlusion. J Electromyogr Kinesiol. 2008; 18(6):931-7
24. Heckmann SM, Heussinger S, Linke JJ, Graef F, Pröschel P. Improvement and long-term stability of neuromuscular adaptation in implant-supported overdentures. Clin Oral Implants Res. 2009 ;20(11):1200-5.

25. Giannakopoulos NN, Corteville F, Kappel S, Rammelsberg P, Schindler HJ, Eberhard L.Functional adaptation ofthe masticatorysystem to implantsupported mandibular overdentures. Clin Oral Implants Res. 2017;28(5):529-534.

26. Schindler HJ, Hellmann D, Giannakopoulos NN, Eiglsperger U, van Dijk JP, Lapatki BG. Localized taskdependent motor-unit recruitment in the masseter. Journal of Oral Rehabilitation.2014; 41: 477 